\title{
A time-resolved model of the mesospheric Na layer: constraints on the meteor input function
}

\author{
J. M. C. Plane \\ School of Environmental Sciences, University of East Anglia, Norwich, UK \\ Received: 17 October 2003 - Published in Atmos. Chem. Phys. Discuss.: 6 January 2004 \\ Revised: 29 March 2004 - Accepted: 29 March 2004 - Published: 16 April 2004
}

\begin{abstract}
A time-resolved model of the Na layer in the mesosphere/lower thermosphere region is described, where the continuity equations for the major sodium species $\mathrm{Na}$, $\mathrm{Na}^{+}$and $\mathrm{NaHCO}_{3}$ are solved explicity, and the other shortlived species are treated in steady-state. It is shown that the diurnal variation of the Na layer can only be modelled satisfactorily if sodium species are permanently removed below about $85 \mathrm{~km}$, both through the dimerization of $\mathrm{NaHCO}_{3}$ and the uptake of sodium species on meteoric smoke particles that are assumed to have formed from the recondensation of vaporized meteoroids. When the sensitivity of the Na layer to the meteoroid input function is considered, an inconsistent picture emerges. The ratio of the column abundance of $\mathrm{Na}^{+}$to $\mathrm{Na}$ is shown to increase strongly with the average meteoroid velocity, because the $\mathrm{Na}$ is injected at higher altitudes. Comparison with a limited set of $\mathrm{Na}^{+}$measurements indicates that the average meteoroid velocity is probably less than about $25 \mathrm{~km} \mathrm{~s}^{-1}$, in agreement with velocity estimates from conventional meteor radars, and considerably slower than recent observations made by wide aperture incoherent scatter radars. The Na column abundance is shown to be very sensitive to the meteoroid mass input rate, and to the rate of vertical transport by eddy diffusion. Although the magnitude of the eddy diffusion coefficient in the $80-90 \mathrm{~km}$ region is uncertain, there is a consensus between recent models using parameterisations of gravity wave momentum deposition that the average value is less than $3 \times 10^{5} \mathrm{~cm}^{2} \mathrm{~s}^{-1}$. This requires that the global meteoric mass input rate is less than about $20 \mathrm{td}^{-1}$, which is closest to estimates from incoherent scatter radar observations. Finally, the diurnal variation in the meteoroid input rate only slight perturbs the Na layer, because the residence time of $\mathrm{Na}$ in the layer is several days, and diurnal effects are effectively averaged out.
\end{abstract}

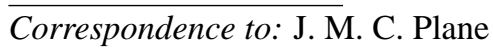

(j.plane@uea.ac.uk)

\section{Introduction}

The first objective in this paper is to describe a new timeresolved model of the sodium layer in the upper mesosphere/lower thermosphere (MLT). We have developed this model, hereafter termed NAMOD, to provide a more realistic description of the input of $\mathrm{Na}$ atoms into the MLT from meteoric ablation, the conversion of $\mathrm{Na}$ atoms into $\mathrm{Na}^{+}$ions and small Na-containing molecules, and the eventual removal of these species from the gas phase via condensation onto particles. The model also permits the behaviour of the Na layer to be analysed on a much shorter time-scale than is possible using traditional steady-state Na models (Plane, 1991; McNeil et al., 1995; Plane et al., 1999). The second objective is to address the large degree of uncertainty, illustrated in this special issue of Atmospheric Chemistry and Physics, concerning the meteoroid velocity distribution and the total meteoroid mass entering the atmosphere. The purpose here is to investigate whether modelling the characteristic features of the Na layer constrains the widely ranging estimates of these meteoroid input parameters.

Figure 1 is a schematic diagram of the gas-phase chemistry of sodium that is believed to take place in the MLT (McNeil et al., 2002). Almost all of these reactions have now been studied in isolation in the laboratory, under conditions appropriate to the MLT (Plane, 2002). Above the atomic Na layer around $90 \mathrm{~km}$, ion chemistry predominates. $\mathrm{Na}$ atoms are ionized mostly by charge transfer with the ambient $\mathrm{NO}^{+}$and $\mathrm{O}_{2}^{+}$ions, together with a small contribution from solar photoionization. $\mathrm{Na}^{+}$is then neutralised by forming clusters which undergo dissociative electron recombination. Below $90 \mathrm{~km}$, $\mathrm{Na}$ becomes converted to the stable reservoir $\mathrm{NaHCO}_{3}$, via a series of steps beginning with the oxidation of $\mathrm{Na}$ by $\mathrm{O}_{3}$ to $\mathrm{NaO}$. As shown in Fig. 1, species such as $\mathrm{NaO}, \mathrm{NaOH}$ and $\mathrm{NaHCO}_{3}$ are converted back to $\mathrm{Na}$ by reaction with $\mathrm{O}$ and $\mathrm{H}$, and also by photolysis. 


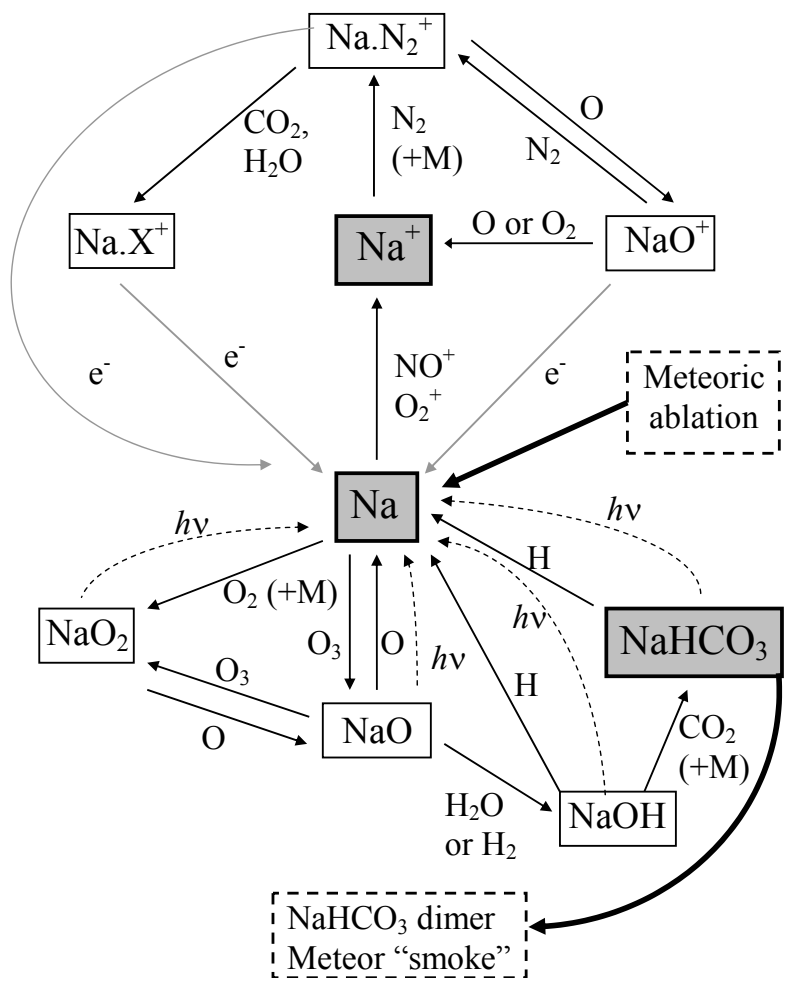

Fig. 1. Schematic drawing of the sodium chemistry in the NAMOD model. The thin solid lines indicate reactions with measured rate coefficients. The broken lines are measured photodissociation reactions. The grey solid lines are dissociative electron recombination reactions with estimated rate coefficients.

The most common type of Na layer model that has been employed is where the metal chemistry is assumed to be in steady state at each height level in the model (Plane, 1991; McNeil et al., 1995; Plane et al., 1999; McNeil et al., 2002). Such a model assumes that the gas-phase chemistry is fast on the time-scale of vertical transport, and that the metal chemistry is closed. That is, all the constituent species cycle between each other, so that no species provides a permanent sink in the upper mesosphere. However, in a recent laboratory study of the photochemistry of sodium species (Self and Plane, 2002), we have found that the major reservoir, $\mathrm{NaHCO}_{3}$, has a sufficiently large photolysis cross-section below $240 \mathrm{~nm}$ that its photolysis lifetime is only a few hours in the MLT. As will be demonstrated in Sect. 2.4, this would cause a large increase in $\mathrm{Na}$ below $90 \mathrm{~km}$ during the day, arising from $\mathrm{NaHCO}_{3}$ photolysis. Because such an increase is not in fact observed (Clemesha et al., 1982; States and Gardner, 2000), the most likely explanation is that $\mathrm{NaHCO}_{3}$ is permanently removed in the 75 to $85 \mathrm{~km}$ region. In the new model to be described here, this removal occurs through the polymerization of $\mathrm{NaHCO}_{3}$ into dimers, and also by the uptake of sodium species onto meteoric smoke particles (Hunten et al., 1980; Kalashnikova et al., 2000). Hence, a steady-state treatment of the chemistry that partitions sodium between $\mathrm{Na}$ and $\mathrm{NaHCO}_{3}$ is no longer appropriate.
The major source of sodium in the MLT is the ablation of sporadic meteoroids, which provide a much greater mass flux than meteor showers (Ceplecha et al., 1998; Baggaley, 2002). Unfortunately, the average daily input of meteoroids into the atmosphere is rather uncertain. Until the 1990s, estimates of the mass flux passing through the beams of meteor radars indicated a figure of about $44 \mathrm{t} \mathrm{d}^{-1}$ over the entire Earth (Hughes, 1978). However, conventional meteor radars actually measure specular reflections from the ion trail created in the atmosphere by the ablating meteoroid, from which the mass and velocity of the meteoroid are derived indirectly (Baggaley, 2002). Furthermore, the wavelength of the radar will only sample a subset of the mass/velocity distribution of the meteoroids. In fact, the mass flux from conventional radar estimates has now been revised upwards by a factor of 2-3 (Hughes, 1997).

The meteoroid mass input rate has also been estimated by other techniques. For instance, measuring the accumulation of iridium in ocean-floor sediments indicates that the meteoric influx could be up to $240 \mathrm{t} \mathrm{d}^{-1}$ (Wasson and Kyte, 1987). More recently, the analysis of small particle impact craters on the Long Duration Exposure Facility (LDEF), an orbital impact detector placed on a spacecraft for several years, has yielded an estimate of $80-130 \mathrm{td}^{-1}$ (Love and Brownlee, 1993; McBride et al., 1999). The median mass of the incoming dust particles was deduced to be $10 \mu \mathrm{g}$, with a median radius of $100 \mu \mathrm{m}$ and a mean entry velocity of about $18 \mathrm{~km} \mathrm{~s}^{-1}$. Single-particle analyses of stratospheric aerosol have shown that half of the particles in the lower stratosphere contain 0.5 to $1.0 \%$ meteoric iron by mass, requiring a total extraterrestrial flux of between 20 and $100 \mathrm{t} \mathrm{d}^{-1}$ (Cziczo et al., 2001). In the past couple of years, high-powered large aperture radars, such as the radio telescope at Arecibo, have reported direct observations of the meteor head echo (i.e. the ball of plasma around the ablating particle as it descends through the atmosphere). This enables measurements of the direction of origin, velocity, deceleration and mass to be made (PellinenWannberg and Wannberg, 1994; Mathews et al., 1997; Close et al., 2000; Janches et al., 2000; Mathews et al., 2001). The observed mass distribution is shifted to smaller mass ranges (median mass $\approx 1 \mu \mathrm{g}$ ) compared with the LDEF results, so that the total incoming mass rate is about $10 \mathrm{td}^{-1}$; that is, 1 order of magnitude lower than the LDEF estimate. The mean entry velocity is also significantly higher, around 40$50 \mathrm{~km} \mathrm{~s}^{-1}$. These conflicting results from the two different types of radar measurement have yet to be resolved.

\section{The time-resolved sodium model (NAMOD)}

\subsection{Sodium chemistry}

The sodium reaction scheme used in NAMOD is illustrated in Fig. 1. The appropriate rate coefficients, listed in Table 1 , are taken from a recent review by the author (Plane, 
Table 1. Gas-phase neutral and ion-molecule reactions of $\mathrm{Na}$ Species contained in the model.

\begin{tabular}{|c|c|c|}
\hline Number & Reaction & Rate coefficient ${ }^{\#}$ \\
\hline & Neutral chemistry & \\
\hline (R1) & $\mathrm{Na}+\mathrm{O}_{3} \rightarrow \mathrm{NaO}+\mathrm{O}_{2}$ & $1.1 \times 10^{-9} \exp (-116 / T)$ \\
\hline (R2) & $\mathrm{NaO}+\mathrm{O} \rightarrow \mathrm{Na}+\mathrm{O}_{2}$ & $2.2 \times 10^{-10}(T / 200)^{1 / 2}$ \\
\hline (R3) & $\mathrm{NaO}+\mathrm{O}_{3} \rightarrow \mathrm{Na}+2 \mathrm{O}_{2}$ & $3.2 \times 10^{-10}(\exp (-550 / T)$ \\
\hline (R4) & $\mathrm{NaO}+\mathrm{H}_{2} \rightarrow \mathrm{NaOH}+\mathrm{H}$ & $1.1 \times 10^{-9} \exp (-1100 / T)$ \\
\hline (R5) & $\mathrm{NaO}+\mathrm{H}_{2} \rightarrow \mathrm{Na}+\mathrm{H}_{2} \mathrm{O}$ & $1.1 \times 10^{-9} \exp (-1400 / T)$ \\
\hline (R6) & $\mathrm{NaO}+\mathrm{H}_{2} \mathrm{O} \rightarrow \mathrm{NaOH}+\mathrm{OH}$ & $4.4 \times 10^{-10} \exp (-507 / T)$ \\
\hline (R7) & $\mathrm{NaOH}+\mathrm{H} \rightarrow \mathrm{Na}+\mathrm{H}_{2} \mathrm{O}$ & $4 \times 10^{-11} \exp (-550 / T)$ \\
\hline (R8) & $\mathrm{NaOH}+\mathrm{CO}_{2}(+\mathrm{M}) \rightarrow \mathrm{NaHCO}_{3}$ & $1.9 \times 10^{-28}(T / 200)^{-1}$ \\
\hline (R9) & $\mathrm{NaHCO}_{3}+\mathrm{H} \rightarrow \mathrm{Na}+\mathrm{H}_{2} \mathrm{CO}_{3}$ & $1.84 \times 10^{-13} T^{0.777} \exp (-1014 / T)$ \\
\hline$(\mathrm{R} 10)$ & $\mathrm{Na}+\mathrm{O}_{2}(+\mathrm{M}) \rightarrow \mathrm{NaO}_{2}$ & $5.0 \times 10^{-30}(T / 200)^{-1.22}$ \\
\hline (R11) & $\mathrm{NaO}_{2}+\mathrm{O} \rightarrow \mathrm{NaO}+\mathrm{O}_{2}$ & $5.0 \times 10^{-10} \exp (-940 / T)$ \\
\hline \multirow[t]{2}{*}{ (R12) } & $2 \mathrm{NaHCO}_{3}(+\mathrm{M}) \rightarrow\left(\mathrm{NaHCO}_{3}\right)_{2}$ & $8.8 \times 10^{-10}(T / 200 \mathrm{~K})^{-0.23}$ \\
\hline & Ion-molecule chemistry & \\
\hline (R20) & $\mathrm{Na}+\mathrm{O}_{2}^{+} \rightarrow \mathrm{Na}^{+}+\mathrm{O}_{2}$ & $2.7 \times 10^{-9}$ \\
\hline$(\mathrm{R} 21)$ & $\mathrm{Na}+\mathrm{NO}^{+} \rightarrow \mathrm{Na}^{+}+\mathrm{NO}$ & $8.0 \times 10^{-10}$ \\
\hline$(\mathrm{R} 22)$ & $\mathrm{Na}^{+}+\mathrm{N}_{2}(+\mathrm{M}) \rightarrow \mathrm{Na} \cdot \mathrm{N}_{2}^{+}$ & $4.8 \times 10^{-30}(T / 200)^{-2.2}$ \\
\hline (R23) & $\mathrm{Na}^{+}+\mathrm{CO}_{2}(+\mathrm{M}) \rightarrow \mathrm{Na} . \mathrm{CO}_{2}^{+}$ & $3.7 \times 10^{-29}(T / 200)^{-2.9}$ \\
\hline (R24) & $\mathrm{Na} \cdot \mathrm{N}_{2}^{+}+\mathrm{X} \rightarrow \mathrm{Na} \cdot \mathrm{X}^{+}+\mathrm{N}_{2}\left(\mathrm{X}=\mathrm{CO}_{2}, \mathrm{H}_{2} \mathrm{O}\right)$ & $6 \times 10^{-10}$ \\
\hline (R25) & $\mathrm{Na} \cdot \mathrm{N}_{2}^{+}+\mathrm{O} \rightarrow \mathrm{NaO}^{+}+\mathrm{N}_{2}$ & $4 \times 10^{-10}$ \\
\hline (R26) & $\mathrm{NaO}^{+}+\mathrm{O} \rightarrow \mathrm{Na}^{+}+\mathrm{O}_{2}$ & $1 \times 10^{-11}$ \\
\hline (R27) & $\mathrm{Na} \cdot \mathrm{O}^{+}+\mathrm{N}_{2} \rightarrow \mathrm{Na} \cdot \mathrm{N}_{2}^{+}+\mathrm{O}$ & $1 \times 10^{-12}$ \\
\hline (R28) & $\mathrm{Na} . \mathrm{O}^{+}+\mathrm{O}_{2} \rightarrow \mathrm{Na}^{+}+\mathrm{O}_{3}$ & $5 \times 10^{-12}$ \\
\hline \multirow[t]{2}{*}{$(\mathrm{R} 29)$} & $\mathrm{Na} . \mathrm{Y}^{+}+\mathrm{e}^{-} \rightarrow \mathrm{Na}+\mathrm{Y}\left(\mathrm{Y}=\mathrm{N}_{2}, \mathrm{CO}_{2}, \mathrm{H}_{2} \mathrm{O}, \mathrm{O}\right)$ & $1 \times 10^{-6}(T / 200)^{-1 / 2}$ \\
\hline & Photochemical reactions & \\
\hline (R30) & $\mathrm{NaO}+h v \rightarrow \mathrm{Na}+\mathrm{O}$ & $5.5 \times 10^{-2}$ \\
\hline (R31) & $\mathrm{NaO}_{2}+h v \rightarrow \mathrm{Na}+\mathrm{O}_{2}$ & $1.9 \times 10^{-2}$ \\
\hline (R32) & $\mathrm{NaOH}+h v \rightarrow \mathrm{Na}+\mathrm{OH}$ & $1.8 \times 10^{-2}$ \\
\hline (R33) & $\mathrm{NaHCO}_{3}+h v \rightarrow \mathrm{Na}+\mathrm{HCO}_{3}$ & $1.3 \times 10^{-4}$ \\
\hline (R34) & $\mathrm{Na}+h v \rightarrow \mathrm{Na}^{+}+\mathrm{e}^{-}$ & $2 \times 10^{-5}$ \\
\hline
\end{tabular}

\# Rate coefficients are taken from a recent review of mesospheric metal chemistry (Plane, 2002), except for R12 (see text). Units: unimolecular, $\mathrm{s}^{-1}$; bimolecular, $\mathrm{cm}^{3}$ molecule $\mathrm{e}^{-1} \mathrm{~s}^{-1}$; termolecular, $\mathrm{cm}^{6}$ molecule $\mathrm{s}^{-2} \mathrm{~s}^{-1}$

2002). Note that a number of minor sodium species (e.g. $\mathrm{NaO}_{3}$ and $\mathrm{NaCO}_{3}$ ) and minor reaction pathways have been omitted from the model in the interests of computing efficiency. This has a negligible effect on the computed atomic Na profiles.

The rate constant for reaction 12 in Table 1, the dimerization of $\mathrm{NaHCO}_{3}$ to form $\left(\mathrm{NaHCO}_{3}\right)_{2}$, was calculated using Rice-Ramsberger-Kassell-Markus (RRKM) theory, which we have recently applied to recombination reactions of metallic species (Plane and Rollason, 2001). The RRKM calculation requires as input the molecular parameters (optimized geometries, moments of inertia, vibrational frequencies and dipole moments) of $\mathrm{NaHCO}_{3}$ and $\left(\mathrm{NaHCO}_{3}\right)_{2}$. These were calculated using the hybrid density functional/Hartree-Fock B3LYP method from within the
Gaussian 98 suite of programs (Frisch et al., 1998), combined with the $6-311+g(2 d, p)$ triple zeta basis set. This is a large, flexible basis set which has both polarization and diffuse functions added to the atoms (Foresman and Frisch, 1996). Fig. 2 shows the optimized geometry of $\left(\mathrm{NaHCO}_{3}\right)_{2}$. There is strong electrostatic binding in the dimer because $\mathrm{NaHCO}_{3}$ has a substantial dipole moment (6.8 Debye). The resulting binding energy of the dimer is $180 \mathrm{~kJ} \mathrm{~mol}^{-1}$ (with an expected uncertainty of $\pm 4 \mathrm{~kJ} \mathrm{~mol}^{-1}$ at this level of theory, Foresman and Frisch, 1996). Moreover, the dimer contains six vibrational modes with very low frequencies $\left(<100 \mathrm{~cm}^{-1}\right)$, which are really free internal rotors. The resulting density of rovibrational states is so high that the recombination reaction to form $\left(\mathrm{NaHCO}_{3}\right)_{2}$ is essentially at the high pressure limit, even in the MLT pressure range of 


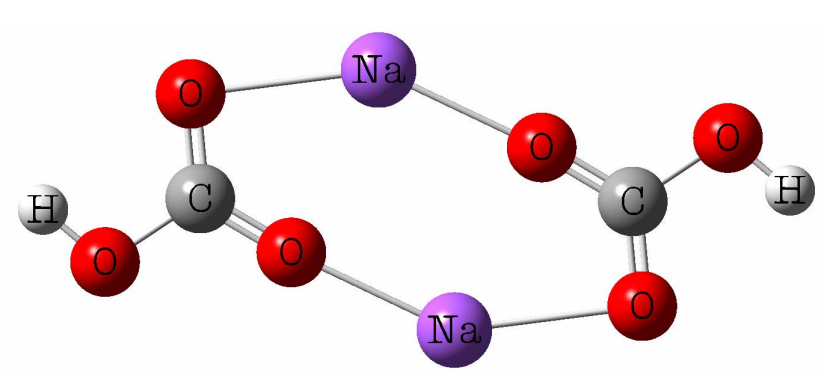

Fig. 2. The sodium bicarbonate dimer, calculated at the B3LYP/6$311+\mathrm{G}(2 \mathrm{~d}, \mathrm{p})$ level of theory. The $\mathrm{Na}$ atoms are $3.2 \AA$ apart, and the $\mathrm{H}$ atoms are $8.9 \AA$ apart.

$10^{-2}-10^{-3}$ mbar. Hence, $k_{12}$ is given by long-range dipoledipole capture theory (Stoecklin and Clary, 1992):

$k_{12}=1.766 \times 10^{6}\left(\frac{\pi}{M_{r}}\right)^{1 / 2}\left(\frac{\mu_{\mathrm{NaHCO}_{3}}{ }^{2}}{4 \pi \varepsilon_{0}}\right)^{2 / 3}\left(k_{B} T\right)^{-1 / 6}$,

where $M_{r}$ is the reduced mass of two $\mathrm{NaHCO}_{3}$ molecules $\left(=6.98 \times 10^{-26} \mathrm{~kg}\right.$ molecule $\left.{ }^{-1}\right), \mu_{\mathrm{NaHCO}_{3}}$ is the dipole moment of $\mathrm{NaHCO}_{3}\left(=2.27 \times 10^{-29} \mathrm{~cm}\right), \varepsilon_{0}$ is the permittivity in a vacuum, and $k_{B}$ is the Boltzmann constant. Note that according to these quantum calculations the dimer should be a sink for sodium, because it will not photolyse at wavelengths above $180 \mathrm{~nm}$, nor react with atomic $\mathrm{H}$ (in constrast to $\mathrm{NaHCO}_{3}$, Cox et al., 2001; Self and Plane, 2002).

In NAMOD, the concentrations of the three major gasphase sodium species, $\mathrm{Na}, \mathrm{NaHCO}_{3}$ and $\mathrm{Na}^{+}$, are determined by full solution of their respective continuity equations. In contrast, all the other sodium species shown in Fig. 1 are short-lived intermediates, and are therefore correctly treated in chemical steady state. The continuity equations of the major species are then given by:

$$
\begin{aligned}
& \frac{d[\mathrm{Na}]}{d t}=I_{\mathrm{abl}}+A\left[\mathrm{NaHCO}_{3}\right]+B\left[\mathrm{Na}^{+}\right]- \\
& \left(C+D+k_{\mathrm{het}}^{\mathrm{Na}}\right)[\mathrm{Na}]-\nabla \Theta^{\mathrm{Na}} \\
& \frac{d\left[\mathrm{NaHCO}_{3}\right]}{d t}=D[\mathrm{Na}]-\left(A+k_{\mathrm{het}}^{\mathrm{NaHCO}_{3}}\right)\left[\mathrm{NaHCO}_{3}\right]- \\
& 2 k_{12}\left[\mathrm{NaHCO}_{3}\right]^{2}-\nabla \Theta^{\mathrm{NaHCO}_{3}} \\
& \frac{d\left[\mathrm{Na}^{+}\right]}{d t}=C[\mathrm{Na}]-\left(B+k_{\mathrm{het}}^{\mathrm{Na}^{+}}\right)\left[\mathrm{Na}^{+}\right]-\nabla \Theta^{\mathrm{Na}^{+}},
\end{aligned}
$$

where $I_{\mathrm{abl}}$ is the rate of injection of Na from meteoric ablation (see below),

$$
A=\left(k_{9}[\mathrm{H}]+J_{33}\right)\left[\mathrm{NaHCO}_{3}\right],
$$

$$
B=\left(k_{22}\left[\mathrm{~N}_{2}\right][\mathrm{M}]\right.
$$

$$
\begin{aligned}
\left(\frac{k_{24}\left(\left[\mathrm{CO}_{2}\right]+\left[\mathrm{H}_{2} \mathrm{O}\right]\right)+k_{29}\left[\mathrm{e}^{-}\right]}{\left.k_{24}\left(\left[\mathrm{CO}_{2}\right]+\left[\mathrm{H}_{2} \mathrm{O}\right]\right)+k_{29}\left[\mathrm{e}^{-}\right]+k_{25}[\mathrm{O}] \frac{\left(k_{26}[\mathrm{O}]+k_{28}\left[\mathrm{O}_{2}\right]\right.}{\left(k_{26}[\mathrm{O}]+k_{28}\left[\mathrm{O}_{2}\right]+k_{27}\left[\mathrm{~N}_{2}\right]\right.}\right)}\right) \\
\left.k_{23}\left[\mathrm{CO}_{2}\right][\mathrm{M}]\right) \\
C=J_{34}+k_{20}\left[\mathrm{O}_{2}^{+}\right]+k_{21}\left[\mathrm{NO}^{+}\right], \\
D=\left(k_{1}\left[\mathrm{O}_{3}\right]+k_{10}\left[\mathrm{O}_{2}\right][\mathrm{M}] \frac{k_{11}[\mathrm{O}]}{k_{11}[0]+J_{31}}\right) \\
\quad\left(\frac{k_{4}\left[\mathrm{H}_{2}\right]+k_{6}\left[\mathrm{H}_{2} \mathrm{O}\right]}{k_{2}[\mathrm{O}]+k_{3}\left[\mathrm{O}_{3}\right]+k_{4}\left[\mathrm{H}_{2}\right]+k_{5}\left[\mathrm{H}_{2}\right]+k_{6}\left[\mathrm{H}_{2} \mathrm{O}\right]+J_{30}}\right) \\
\left(\frac{k_{8}\left[\mathrm{CO}_{2}\right][\mathrm{M}]}{J_{32}+k_{7}[\mathrm{H}]+k_{8}\left[\mathrm{CO}_{2}\right][\mathrm{M}]}\right) .
\end{aligned}
$$

$k_{\text {het }}^{\mathrm{X}}$ is the first-order rate of uptake of species $\mathrm{X}$ on meteoric smoke particles (see below), and $\nabla \Phi^{\mathrm{X}}$ is the divergence of the vertical flux of species X.

The transport of all the sodium constituents is then assumed to be governed by the same eddy diffusion coefficient up to the turbopause at about $100 \mathrm{~km}$, and the vertical flux of species $\mathrm{X}$ at height $z$ is given by

$\Phi^{\mathrm{X}}=-K_{z z}\left(\frac{\partial[\mathrm{X}]}{\partial z}+[\mathrm{X}]\left(\frac{1}{\mathrm{H}}+\frac{1}{T} \frac{\partial T}{\partial z}\right)\right)$,

where $K_{z z}$ is the vertical eddy diffusion coefficient, $H$ is the atmospheric scale height, and $T$ the temperature. Note that for this study we are concerned with averaging over relatively long periods (hours to days), so that short-term fluctuations in the meteor ablation rate and atmospheric turbulence are averaged out. Above the turbopause, molecular diffusion dominates over eddy diffusion, and $K_{z z}$ and $H$ in Eq. (5) are replaced by $D_{\mathrm{X}}$ and $H_{\mathrm{X}}$, the molecular diffusion coefficient and the scale height of the individual species $\mathrm{X}$, respectively (Chabrillat et al., 2002). NAMOD is 1 dimensional, extending from 65 to $110 \mathrm{~km}$ with a height resolution of $0.5 \mathrm{~km}$. Equations (2)-(4) are integrated with a 10 min time step using a time-implicit integration scheme (Shimazaki, 1985). The changing diurnal concentration profiles of $K_{z z}$ and the background mesospheric species that control the sodium chemistry $\left(\mathrm{H}, \mathrm{O}, \mathrm{O}_{3}, \mathrm{NO}^{+}\right.$, $\mathrm{e}^{-}$etc. $)$are read in every 20 model minutes (see below). All model runs shown here were integrated over 20 model days, for the conditions of January, $40^{\circ} \mathrm{N}$.

\subsection{Background mesospheric constituents}

In order to compute a consistent set of concentration profiles for the background species, a separate mesospheric model (MESOMOD) was run off-line. MESOMOD is also 1 dimensional, extending from 65 to $110 \mathrm{~km}$ with a height resolution of $0.5 \mathrm{~km}$. It contains a full treatment of the odd 
oxygen and hydrogen chemistry in the MLT, with rate coefficients taken from the NASA/JPL compilation (DeMore et al., 1997). The vertical eddy diffusion coefficient is taken off-line from a 3D global model, TIME-GCM (Kaufmann et al., 2002). This model also supplies the $\mathrm{H}_{2} \mathrm{O}, \mathrm{H}_{2}$ and $\mathrm{CO}_{2}$ mixing ratios at the lower boundary $(65 \mathrm{~km})$. Parameterised codes for the photolysis of $\mathrm{O}_{3}, \mathrm{H}_{2} \mathrm{O}, \mathrm{HO}_{2}, \mathrm{H}_{2} \mathrm{O}_{2}$, and $\mathrm{O}_{2}$ at Lyman- $\alpha$ and in the Schumann-Runge continuum, are used (Shimazaki, 1985; Brasseur and Solomon, 1998). The photolysis of $\mathrm{O}_{2}$ in the Schumann-Runge bands is calculated using a recent formalism (Koppers and Murtagh, 1996). MESOMOD uses time-implicit integration with a 2 min time step, and was run for 5 model days before a set of diurnal concentration profiles was recorded every $20 \mathrm{~min}$ for input into NAMOD. Note that because the concentration of sodium species is at least 4 orders of magnitude less than species such as $\mathrm{O}_{3}$ or $\mathrm{H}$ in the MLT, the background chemistry is essentially decoupled from the sodium. Profiles of $\mathrm{NO}^{+}, \mathrm{O}_{2}^{+}$ and $\mathrm{e}^{-}$are input off-line for the appropriate year and time-ofday from the International Reference Ionosphere 2000 (Bilitza, 2003).

\subsection{Meteoroid ablation model}

The physics of meteoroid ablation, which occurs because the very high entry velocities of meteoroids lead to rapid heating by collision with air molecules, has been treated in detail by several investigators (Hunten et al., 1980; Love and Brownlee, 1991; Kalashnikova et al., 2000; McNeil et al., 2002). The problem becomes reasonably tractable for particles less than about $250 \mu \mathrm{m}$ in radius, because heat conductivity through the particle is fast enough for the particle to be treated as isothermal (Love and Brownlee, 1991). Most of the total mass of cosmic dust is made up from particles with masses less than $100 \mu \mathrm{g}$ (Love and Brownlee, 1993). Assuming a density of $2 \times 10^{3} \mathrm{~kg} \mathrm{~m}^{-3}$ (typical of an ordinary chondrite), a $250 \mu \mathrm{m}$ meteoroid has a mass of $130 \mu \mathrm{g}$, thereby justifying the neglect of heat conductivity.

The frictional heating of the meteoroid by collisions with air molecules is balanced by radiative losses, and by the absorption of heat energy through temperature increases, melting, phase transitions, and vaporization. In order to calculate these terms, parameters such as the meteoroid shape, density, and composition are needed (Rietmeijer, 2000, 2002). In NAMOD it is assumed that most of the extra-terrestrial material has the composition of ordinary chondrites. If the particles is spherical (i.e. the shape factor is 1.2), then the energy balance equation is given by (Jones and Kaiser, 1966):

$\frac{1}{2} \Lambda \rho_{a} v^{3}=4 \sigma \varepsilon\left(T_{s}^{4}-T_{a}^{4}\right)+\frac{4}{3} R \rho_{m} C \frac{d T_{m}}{d t}$.

The left-hand side of Eq. (1) represents the frictional heating term, where $\Lambda(=0.5)$ is the heat transfer coefficient or fraction of the total kinetic energy of the air molecules that is transferred to the meteoroid, $\rho_{a}$ is the atmospheric density, and $v$ is the meteoroid velocity. The first term on the right-hand side describes the radiative losses, where $\sigma$ is Stefan's constant and $\varepsilon$ is the emissivity of the meteoroid $\left(\sigma \varepsilon=5.7 \times 10^{-8} \mathrm{~J} \mathrm{~m}^{-2} \mathrm{~s}^{-1}\right), T_{s}$ is the surface temperature of the meteoroid, and $T_{a}$ is the temperature of the earth's lower atmosphere for the fraction of meteoroid surface pointing earthwards, and the temperature of deep space for the rest of the particle surface (in practice, $T_{s}>>T_{a}$ and so setting $T_{a}$ to zero is a good approximation). Small particles will not be able to radiate efficiently when their size is comparable to or smaller than the emission wavelength $\lambda$ (i.e. $2 \pi R / \lambda<1$, where $\mathrm{R}$ is the radius of the meteoroid and $\lambda$ is the wavelength of the emitted radiation). Their emission rate will then depart from Stefan's Law (Bohren and Huffman, 1983), causing them to heat more rapidly and hence ablate more efficiently. A black body at $1000 \mathrm{~K}$ has a peak emission at $2.9 \mu \mathrm{m}$, so that only particles smaller than about $1 \mu \mathrm{m}$ should deviate from Stefan's Law at this temperature (Rizk et al., 1991). However, these small particles contribute only about $10 \%$ of the total meteoroid mass (according to the LDEF experiment (McBride et al., 1999)), so that the effect of reduced heat loss from these particles should cause only a slight increase in the total ablation rate.

The second term represents the energy losses due to heating of the particle, where $\rho_{m}\left(=2 \times 10^{3} \mathrm{~kg} \mathrm{~m}^{-3}\right)$ the meteoroid density, $C\left(=1 \times 10^{3} \mathrm{~J} \mathrm{~K}^{-1} \mathrm{~kg}^{-1}\right)$ the meteoroid specific heat, $T_{m}$ the mean temperature of the particle, and $t$ is the time. Note that vaporization is treated separately (see equation 8 below). The change in velocity of the meteoroid is given by

$$
\frac{d v}{d t}=-\frac{\Gamma \rho_{a} \pi R^{2} v^{2}}{m}+\frac{\pi}{\left(z+r_{e}\right)^{2}} .
$$

The first term on the right-hand side describes deceleration, where $\Gamma$ is the atmospheric drag parameter $(=1.2)$ and $m$ is the meteoroid mass. The second term describes gravitational acceleration of the particle, where $z$ is the height in the atmosphere, $r_{e}\left(=6.378 \times 10^{6} \mathrm{~m}\right)$ is the radius of the earth, and $\mu\left(=3.99 \times 10^{14} \mathrm{~m}^{3} \mathrm{~s}^{-2}\right)$ is the gravitational constant of the earth. In the present model, all meteoroids enter the atmosphere at $37^{\circ}$ to the zenith.

Equation (6) shows that for very small particles, the heat capacity term will be much smaller than the radiative loss term, in which case the meteoroid will not become hot enough to ablate. This is the case for all particles smaller than $100 \mathrm{~nm}$. A $1 \mu \mathrm{m}$ particle must enter the atmosphere at over $40 \mathrm{~km} \mathrm{~s}^{-1}$ in order to heat up to $1200 \mathrm{~K}$, the temperature at which volatile elements such as $\mathrm{Na}$ begin to evaporate (Fegley and Cameron, 1987). All meteoroids larger than $10 \mu \mathrm{m}$ will reach this ablation temperature. Figure 3 a shows the altitude at which a $10 \mu \mathrm{g}$ particle $(R \approx 100 \mu \mathrm{m})$ reaches temperatures between 500 and $2500 \mathrm{~K}$, over the range of possible meteoroid entry velocities. Note that particles which originate within the solar system must have entry velocities that range from $11.5 \mathrm{~km} \mathrm{~s}^{-1}$, for a particle in the same orbit as the 

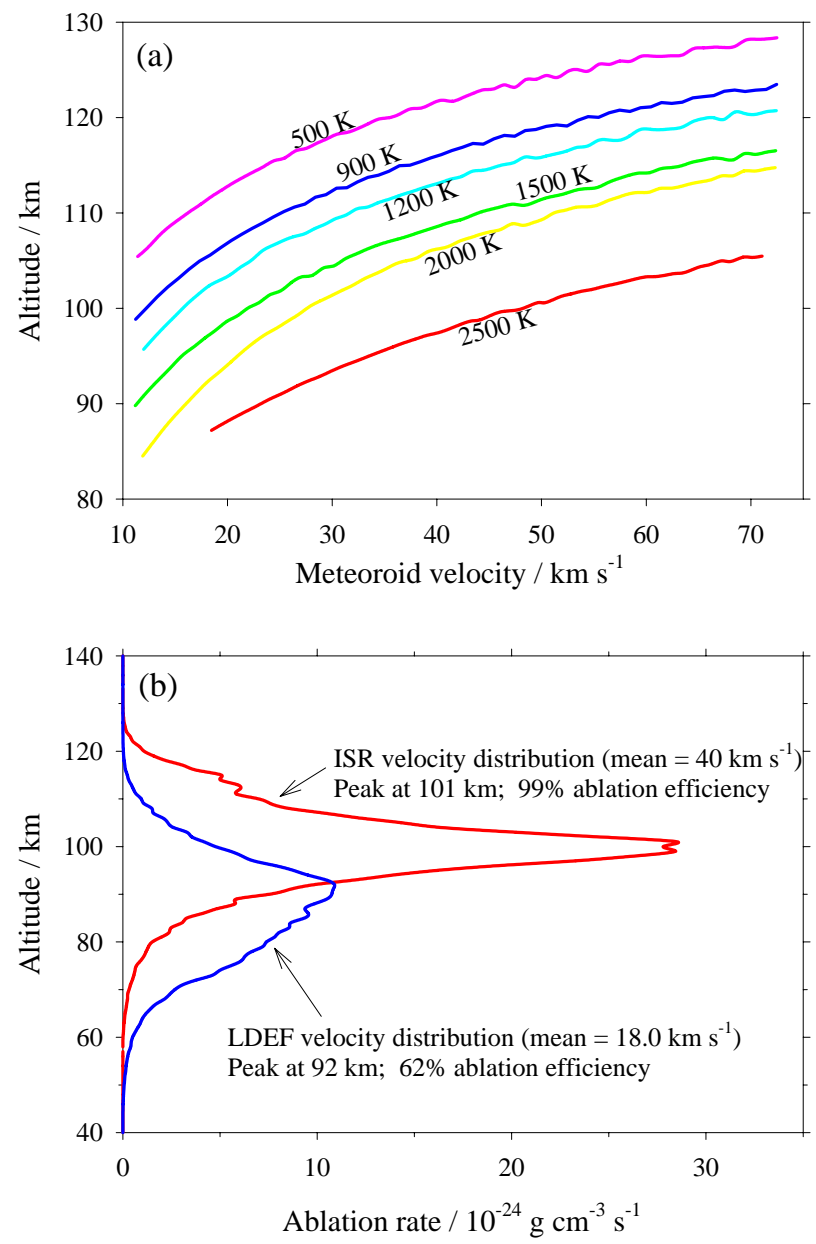

Fig. 3. (a) The height at which a $10 \mu \mathrm{g}$ meteoroid reaches the temperature shown on each of the curves, as a function of meteoroid entry velocity. (b) Height profiles of the total mass ablation rate for the LDEF meteoroid size distribution (reduced by $85 \%$ in all mass ranges to give a global input of $\left.12.1 \mathrm{t} \mathrm{d}^{-1}\right)$, calculated using the assumed LDEF velocity distribution (blue line), or the LDEF velocity distribution shifted by $22 \mathrm{~km} \mathrm{~s}^{-1}$ to simulate the velocity distribution observed by incoherent scatter radars (red line).

Earth, to $72 \mathrm{~km} \mathrm{~s}^{-1}$ for a particle in a retrograde orbit (Baggaley, 2002).

Most of the models developed for estimating the meteoric metal input into the atmosphere (Hunten et al., 1980; Plane, 1991; McNeil et al., 1995; McNeil et al., 2002) assume that the relative metallic abundances in the ablated vapour are given by their meteoritic abundances. The major metallic constituents by weight are then: $\mathrm{Mg} 12.5 \%, \mathrm{Fe} 11.5 \%$, Al 1.7\%, Ni 1.5\%, Ca 1.0\%, Na 0.6\% (Mason, 1971). A more realistic approach involving fractionation has been proposed recently, with the relatively volatile elements such as $\mathrm{Na}$ and $\mathrm{K}$ evaporating first and refractory elements (such as Ca) evaporating last (McNeil et al., 1998). This differential ablation scheme, which is based on planetary fractionation models (Fegley and Cameron, 1987), is able to explain the large depletion of $\mathrm{Ca}$ to $\mathrm{Na}$ observed in meteor trails (von Zahn et al., 1999).

The present model contains the following simple treatment of differential ablation. When $T_{s}$ reaches $1200 \mathrm{~K}$, further frictional heat input to the particle is balanced by vaporization and radiative cooling, and no further temperature rise occurs until the initial $20 \%$ of the meteoroid mass has evaporated. This is determined from the relation

$\xi \frac{d m}{d t}=-\frac{1}{2} \Lambda \rho_{a} v^{3}+4 \sigma \varepsilon\left(T_{s}^{4}-T_{a}^{4}\right)$,

where $\xi\left(=3 \times 10^{6} \mathrm{~J} \mathrm{~kg}^{-1}\right)$ is the heat of sublimation of the meteoroid. All of the $\mathrm{Na}$ is assumed to evaporate in the first $5 \%$ of this fraction. Evaporation then ceases until $T_{S}$ reaches $2100 \mathrm{~K}$, when $78 \%$ of the mass evaporates. The final $2 \%$, containing most the $\mathrm{Ca}$ and other refractory elements, then evaporates if $T_{S}$ reaches $2500 \mathrm{~K}$.

Figure $3 b$ shows the mass ablation rate as a function of altitude, for the meteoroid mass and velocity distribution estimated from the LDEF experiment (McBride et al., 1999). This will be termed the LDEF profile. The peak rate of ablation occurs at $91 \mathrm{~km}$, and about $62 \%$ of the total incoming material vaporizes. The unablated fraction consists of particles that are too small, or that enter the atmosphere too slowly, to vaporize completely. This ablation profile is similar in peak height and width to that observed by conventional meteor radars, such as in a recent paper using the $53.5 \mathrm{MHz}$ radar at Kühlungsborn, a mid-latitude site (Singer et al., 2003). Also shown in Fig. $3 \mathrm{~b}$ is the ablation profile predicted if the velocity distribution is shifted so that the mean velocity increases from 18 to $40 \mathrm{~km} \mathrm{~s}^{-1}$, in line with the large aperture radar measurements (Pellinen-Wannberg and Wannberg, 1994; Mathews et al., 1997; Close et al., 2000; Janches et al., 2000). This ablation profile, which will be referred to as the ISR profile, now peaks just above $100 \mathrm{~km}$, and $99 \%$ of the material ablates. The profile is in sensible accord with a very recent micrometeor profile from the Arecibo Observatory (Mathews et al., 2003), where the observed broad velocity distribution between 40 and $60 \mathrm{~km} \mathrm{~s}^{-1}$ results in the profile peaking even higher in the atmosphere at $106 \mathrm{~km}$. In the NAMOD model, these profiles are then modulated with a diurnal and seasonal variation taken from a recent radio meteor survey (Yrjola and Jenniskens, 1998).

\subsection{Removal of sodium species from the gas phase}

Figure 4a illustrates the modelled Na layer at midday and midnight, when no permanent removal of sodium species is included in NAMOD i.e. $k_{12}$ and $k_{\text {het }}^{\mathrm{X}}$ are set to zero. This shows that the Na layer always peaks below $90 \mathrm{~km}$, that the peak moves $2 \mathrm{~km}$ lower in daytime, and that the underside of the layer has a scale height less than $1 \mathrm{~km}$. These model predictions are not in accord with lidar observations of the diurnal behaviour of the layer (Clemesha et al., 1982; States 
and Gardner, 2000). However, if removal of $\mathrm{NaHCO}_{3}$ by dimerization is now switched on in the model, Fig. 4b shows that the layer now peaks around $90 \mathrm{~km}$ with little diurnal variation in the peak height, and the layer has an approximately Gaussian shape, in much better agreement with observations (Plane et al., 1999; States and Gardner, 2000).

Figure $4 \mathrm{c}$ illustrates the effect of also switching on the heterogeneous removal of the three major sodium species on meteoric smoke particles. These particles have been proposed to form through the recondensation of vaporized meteoroids (Hunten et al., 1980; Kalashnikova et al., 2000). The height profile of $1.3 \mathrm{~nm}$ radius smoke particles, illustrated in Fig. 4c, is calculated in NAMOD from the total ablated meteoroid flux (Hunten et al., 1980). Note that these small particles, which are really macromolecules (e.g. a cluster of 60 $\mathrm{FeSiO}_{3}$ molecules would have a radius of about $1.3 \mathrm{~nm}$ ), cannot be much larger or their sedimentation velocity would increase to the point where they could not remain at significant concentrations above $80 \mathrm{~km}$ (Hunten et al., 1980).

The uptake of sodium species on these smoke particles is likely to be highly efficient, and an uptake coefficient of 0.5 is assumed in NAMOD. In fact, $\mathrm{NaHCO}_{3}$ and $\mathrm{Na}^{+}$should adsorb readily because of electrostatic effects, and we have recently shown in the laboratory that $\mathrm{Na}$ atoms stick with high efficiency on a silica surface (B. J. Murray and J. M. C. Plane, University of East Anglia). As shown in Fig. 4c, there is now less than $0.5 \mathrm{~km}$ change in the peak height between midnight and midday. In contrast, the centroid height of the layer decreases from $92.5 \mathrm{~km}$ to $91.0 \mathrm{~km}$ in daytime, which is in good accord with observations (Clemesha et al., 1982). This decrease arises largely because during daytime there is additional ionization of $\mathrm{Na}$ on the topside, as well as photolysis of $\mathrm{NaHCO}_{3}$ on the bottomside. The Na concentration of around 5100 atom $\mathrm{cm}^{-3}$ at the layer peak, and the column density of $5.9 \times 10^{9}$ atom $\mathrm{cm}^{-2}$, are typical values during winter at midlatitudes (Plane, 1991).

Note that in these model runs the LDEF velocity distribution was used with a diurnal average $\mathrm{Na}$ input flux from ablation set to $3.8 \times 10^{3}$ atom $\mathrm{cm}^{-2} \mathrm{~s}^{-1}$, equivalent to a global meteoroid mass input rate of $12.1 \mathrm{t} \mathrm{d}^{-1}$. This $\mathrm{Na}$ input flux, together with permanent removal of sodium by heterogeneous uptake and dimerization of $\mathrm{NaHCO}_{3}$, is the base case in the sensitivity tests that follow.

\section{Sensitivity tests on the meteor input function}

In this section the NAMOD model is used to investigate which features of the Na layer are particularly sensitive to the meteoroid entry velocity and mass flux. The sensitivity of the layer to diurnal variations in the meteoroid flux will also be considered.

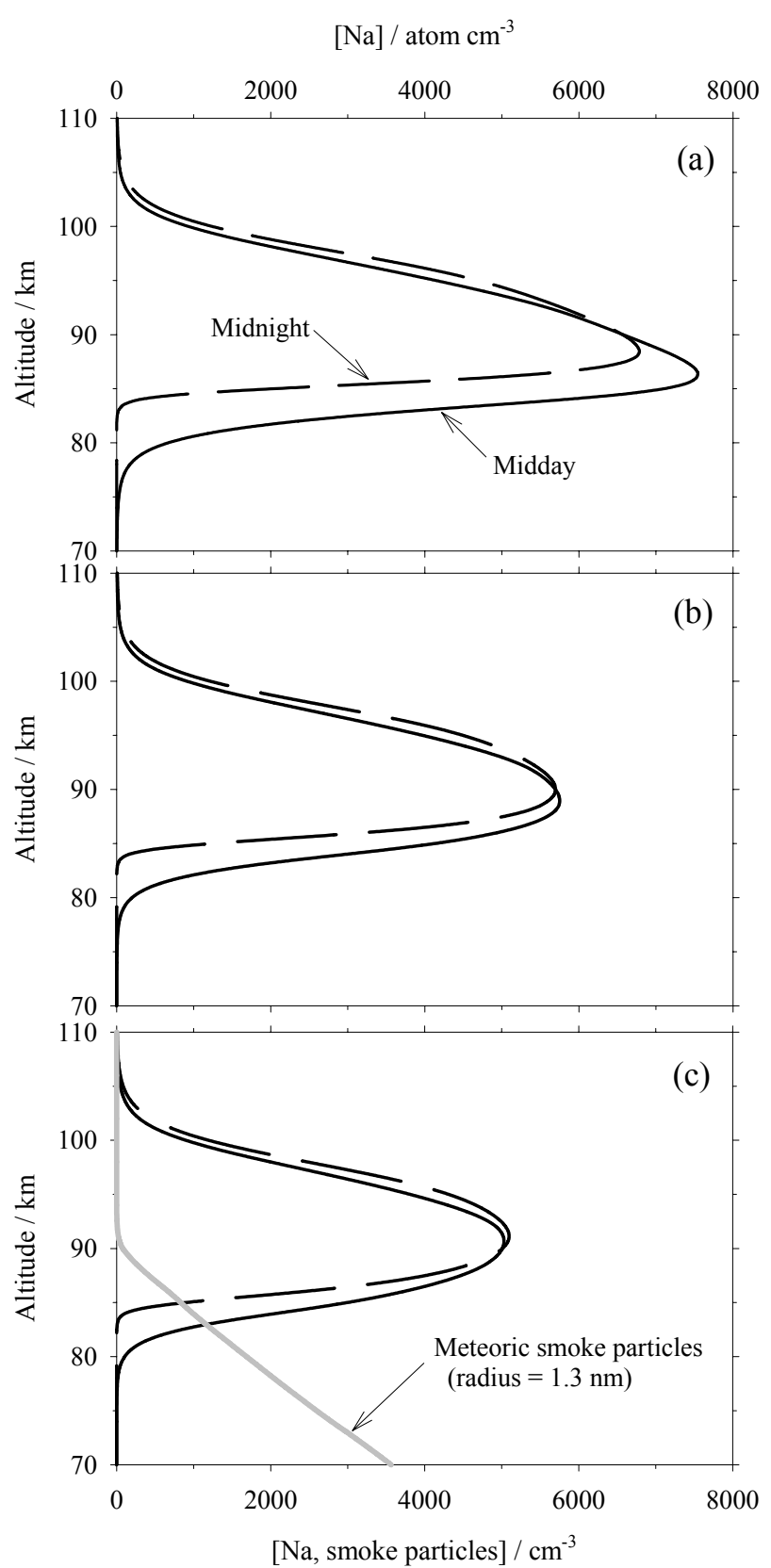

Fig. 4. Modelled height profiles of the $\mathrm{Na}$ layer at midday and midnight, for $40^{\circ} \mathrm{N}$, January: (a), no permanent sinks for gasphase sodium species; (b), dimerization of $\mathrm{NaHCO}_{3}$ is included; (c), dimerization of $\mathrm{NaHCO}_{3}$ and permanent removal of sodium species on meteoric smoke particles of radius $1.3 \mathrm{~nm}$ are included. The smoke particle profile is depicted by the solid grey line. The

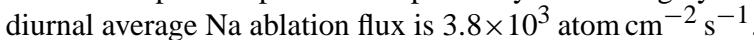

\subsection{Entry velocity}

Figure 5a shows the profiles of the Na injection rate, $I_{\mathrm{abl}}$, predicted for the LDEF and ISR velocity distributions. These profiles peak at altitudes of 94 and $112 \mathrm{~km}$, respectively, a 

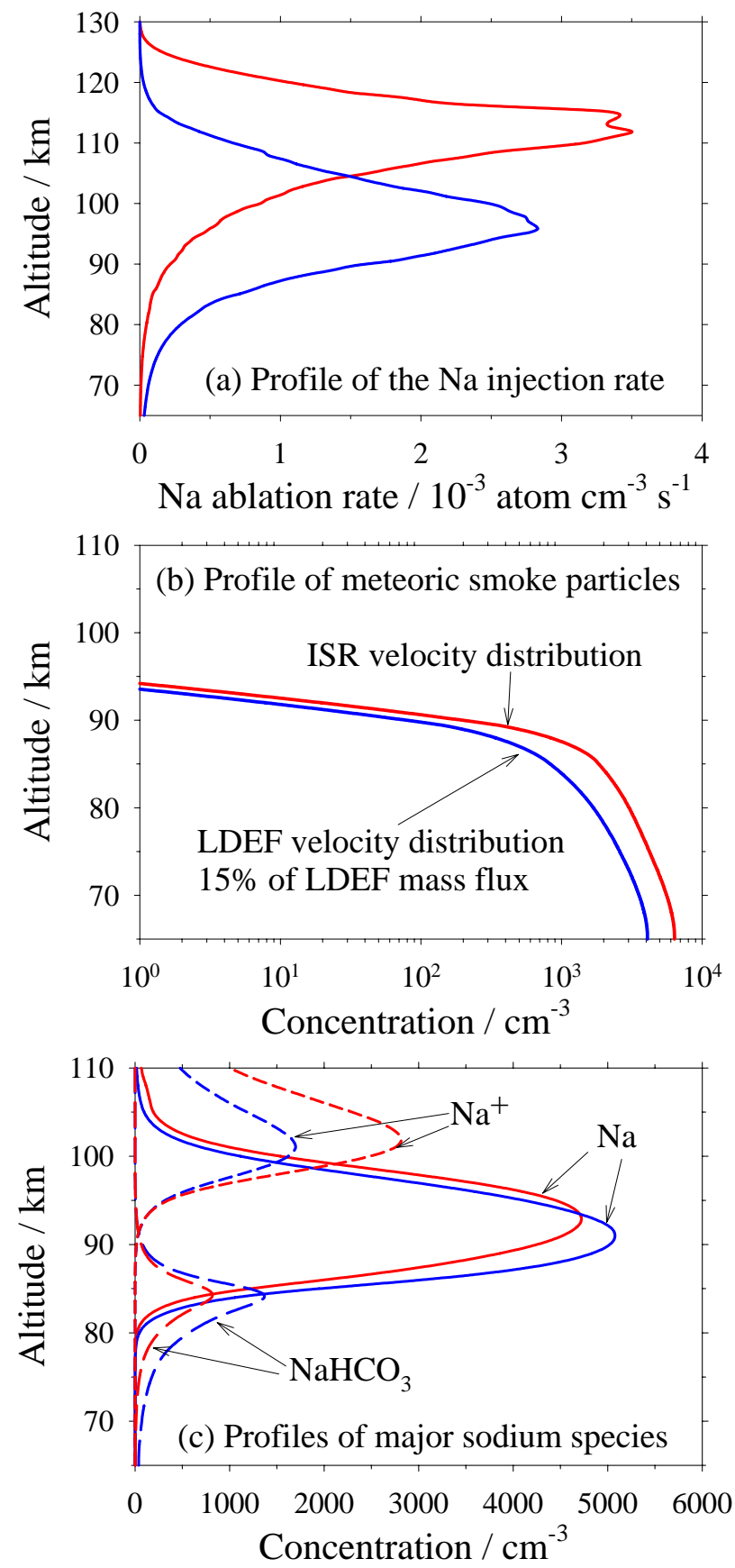

Fig. 5. (a) Height profiles of the Na input rate from meteor ablation, calculated for the LDEF meteoroid size distribution (reduced by $85 \%$ in all mass ranges to give a global input of $12.1 \mathrm{td}^{-1}$ ) and the LDEF velocity distribution (blue line), or the LDEF velocity distribution shifted by $22 \mathrm{~km} \mathrm{~s}^{-1}$ to simulate the velocity distribution observed by incoherent scatter radars (red line). (b) Height profiles of the concentration of $1.3 \mathrm{~nm}$ radius meteoric smoke particles, for the two velocity distributions in (a). (c) Diurnally-averaged height profiles of $\mathrm{Na}, \mathrm{Na}^{+}$and $\mathrm{NaHCO}_{3}$, for the two velocity distributions in (a). Conditions are $40^{\circ} \mathrm{N}$, January. substantial separation of $18 \mathrm{~km}$. Note that these injection profiles peak at altitudes 3 and $10 \mathrm{~km}$ higher than the respective mass ablation rate profiles in Fig. 3b, because all the $\mathrm{Na}$ is assumed to ablate in the first $5 \%$ of vaporized mass. Figure $5 \mathrm{~b}$ illustrates the predicted profiles of meteoric smoke particles for the two velocity distributions. Because the sedimentation velocity of $1.3 \mathrm{~nm}$ particles becomes significant above $90 \mathrm{~km}\left(>2 \mathrm{~cm} \mathrm{~s}^{-1}\right)$, the profiles both exhibit a sharp cut-off between 85 and $90 \mathrm{~km}$. More particles are produced in the ISR profile because essentially all the incoming meteoroid mass ablates, compared with only $62 \%$ for the LDEF profile.

Figure $5 \mathrm{c}$ illustrates the predicted diurnally-averaged height profiles of $\mathrm{Na}, \mathrm{Na}^{+}$and $\mathrm{NaHCO}_{3}$ for the two velocity distributions. One effect of the greater number of smoke particles in the ISR case is to reduce both $\mathrm{NaHCO}_{3}$ and $\mathrm{Na}$ by increased heterogeneous uptake below $90 \mathrm{~km}$, with the result that the peak of the Na layer moves up from 91 to $93 \mathrm{~km}$. However, although a peak of $93 \mathrm{~km}$ is about $2 \mathrm{~km}$ higher than typically observed in mid-latitude winter conditions (Plane et al., 1999), this is probably not of significance because of uncertainties in the smoke profile and uptake coefficients of the sodium species. Of greater interest is the ratio of the column abundances of $\mathrm{Na}^{+}$to $\mathrm{Na}$, which increases from 0.27 in the LDEF case to greater than 0.5 for the ISR velocity distribution. This occurs because in the ISR case most of the $\mathrm{Na}$ is injected well above $100 \mathrm{~km}$ (Fig. 5a), where it is converted to $\mathrm{Na}^{+}$(by charge transfer with $\mathrm{NO}^{+}$and $\mathrm{O}_{2}^{+}$) more rapidly than being transported downwards by eddy diffusion.

Although there is only a limited set of rocket-borne mass spectrometric measurements of $\mathrm{Na}^{+}$ions in the MLT (Kopp, 1997), we have averaged the data from nine flights at midand high latitudes to obtain an approximate $\mathrm{Na}^{+}$column abundance of $1.1 \times 10^{9} \mathrm{~cm}^{-2}$. That is, the $\mathrm{Na}^{+} / \mathrm{Na}$ ratio should be around $0.2-0.25$. Comparison with the NAMOD predictions above implies that an average entry velocity around $40 \mathrm{~km} \mathrm{~s}^{-1}$ is significantly too high. In order to produce a $\mathrm{Na}^{+} / \mathrm{Na}$ ratio below 0.3 , most $\mathrm{Na}$ must be injected below $100 \mathrm{~km}$, requiring that the average entry velocity be less than about $25 \mathrm{~km} \mathrm{~s}^{-1}$.

It should be noted that lidar observations of $\mathrm{Na}$ in freshlyablated meteor trails recorded a height distribution with a centroid height of $89.0 \pm 0.3 \mathrm{~km}$, and a root-mean-square width of $3.3 \pm 0.2 \mathrm{~km}$ (Kane and Gardner, 1993). In comparison, the $\mathrm{Na}$ ablation profile from the LDEF mass/velocity distribution (Fig. 5a) is both higher (centroid $=96.5 \mathrm{~km}$ ) and broader ( $\mathrm{rms}$ width $=8.3 \mathrm{~km}$ ). However, as Kane and Gardner pointed out, the lidar observations are biased towards larger particles that produce observable concentrations of $\mathrm{Na}$ above the background Na layer. Furthermore, the rate of molecular diffusion varies inversely with the pressure, so that trails produced higher up are increasingly likely to decay by diffusion into the background metallic layers before they can be observed. 


\subsection{Total meteoroid mass}

In Sect. 1 there is a discussion of the widely differing estimates of the total meteoroid mass input to the atmosphere, which range from less than 10 to over $200 \mathrm{t} \mathrm{d}^{-1}$. The $\mathrm{Na}$ column abundance is clearly sensitive to the meteoroid flux, and so it might be thought that application of a model such as NAMOD would provide a means of constraining these flux estimates. However, the Na column abundance is also controlled by the chemistry in the MLT, and the rate of downward transport by eddy diffusion. While laboratory experiments appear to have placed the gas-phase chemistry on reasonably firm ground (Plane, 2002), there is currently uncertainty regarding the appropriate values of $K_{z z}$ to use for describing vertical transport in the MLT. Atmospheric models which include a parameterisation of gravity wave momentum deposition predict an average value for $K_{z z}$ between 80 and $90 \mathrm{~km}$ of $(1-4) \times 10^{5} \mathrm{~cm}^{2} \mathrm{~s}^{-1}$ (Garcia and Solomon, 1994; Chabrillat et al., 2002; Kaufmann et al., 2002). In contrast, estimates based on measured energy dissipation rates in the MLT find values up to an order of magnitude greater (Hocking, 1990).

Figure 6a shows the effect on the diurnally-averaged $\mathrm{Na}$ layer of increasing $K_{z z}$ by factors of 2, 5, 10 and 20, for a constant meteoric mass input $\left(12.1 \mathrm{td}^{-1}\right)$. Note the marked reduction in the column abundance and peak density, with increasing $K_{z z}$. The peak height of the layer also decreases from 91.0 to $88.5 \mathrm{~km}$. However, this change is comparatively modest, and because the peak height is also sensitive to uncertainties in the chemistry, it is not as useful a test of the balance between the meteoric input flux and downward transport by eddy diffusion.

Figure $6 \mathrm{~b}$ is a contour plot showing the $\mathrm{Na}$ column abundance predicted by NAMOD for a range of meteoroid mass inputs $\left(1.4\right.$ to $\left.170 \mathrm{td}^{-1}\right)$ and values of $K_{z z}\left(8 \times 10^{4}\right.$ to $4.6 \times 10^{6} \mathrm{~cm}^{2} \mathrm{~s}^{-1}$ ) between 80 and $90 \mathrm{~km}$. Note that the concentration profile of meteoric smoke particles is calculated separately for each of these model runs. This plot demonstrates the sensitivity of the $\mathrm{Na}$ column abundance to both parameters. However, inspection of Fig. $6 \mathrm{~b}$ shows that the typical Na column abundance of $5 \times 10^{9} \mathrm{~cm}^{-2}$ can be produced from a range of combinations of these parameters. For instance, this column abundance is predicted to result from a meteoroid mass input around $12 \mathrm{td}^{-1}$, as estimated by the ISR observations (Sect. 2.3), combined with a low $K_{z z}$ value around $2 \times 10^{5} \mathrm{~cm}^{2} \mathrm{~s}^{-1}$, as predicted by gravity wave momentum deposition models (Kaufmann et al., 2002). But the same column abundance can be produced by the higher mass input estimated from conventional meteor radars (40-50 $\mathrm{t} \mathrm{d}^{-1}$ ) (Hughes, 1978), if a larger value of $K_{z z}$ around $10^{6} \mathrm{~cm}^{2} \mathrm{~s}^{-1}$ is adopted, consistent with measured energy dissipation rates (Hocking, 1990). Finally, mass input rates above $100 \mathrm{td}^{-1}$, estimated from the LDEF experiment (Love and Brownlee, 1993) and the accumulation of iridium in deep-sea sediments (Wasson and Kyte, 1987), require very
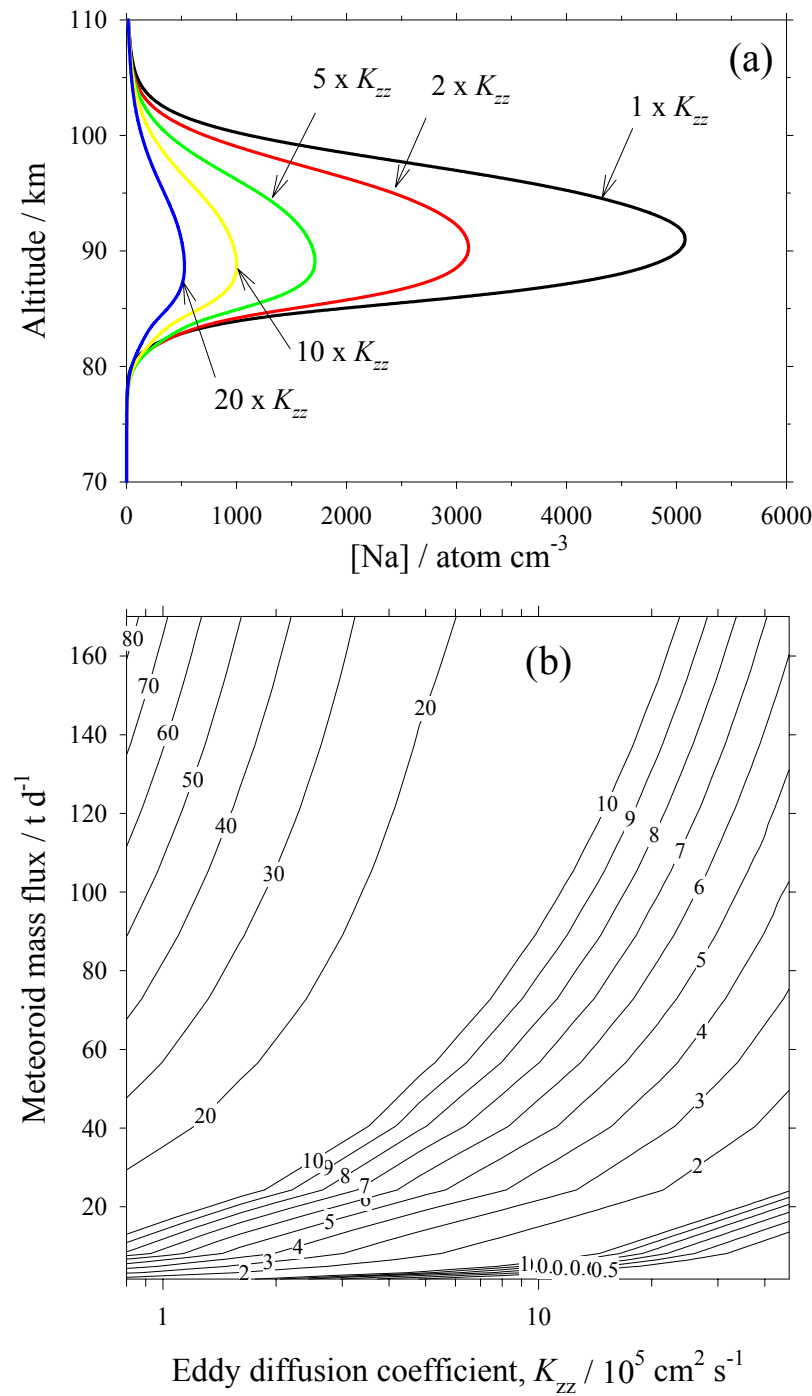

Fig. 6. (a) Diurnally-averaged Na profiles where the eddy diffusion coefficient profile is multiplied by the factor indicated. The global meteoroid mass input rate is $12.1 \mathrm{td}^{-1}$. (b) Contour plot of

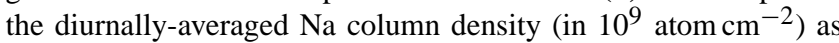
a function of the global meteoroid mass input rate (assuming the LDEF mass and velocity distribution), and the average eddy diffusion coefficient between 80 and $90 \mathrm{~km}$. The typical observed column density is about $5 \times 10^{9}$ atom $\mathrm{cm}^{-2}$. Conditions: $40^{\circ} \mathrm{N}$, January.

large values of $K_{z z}\left(>3 \times 10^{6} \mathrm{~cm}^{2} \mathrm{~s}^{-1}\right)$ in order to limit the build up of $\mathrm{Na}$ in the MLT.

Since such large values of the eddy coefficient are greater than both experimental (Hocking, 1990) and theoretical (Kaufmann et al., 2002) estimates of $K_{z z}$, it seems that the global mass input rate must be below $100 \mathrm{t} \mathrm{d}^{-1}$. Furthermore, a recent modelling study of the significant decrease in the $\mathrm{CO}_{2}$ mixing ratio above $80 \mathrm{~km}$ has demonstrated that the average $K_{z z}$ between 80 and $90 \mathrm{~km}$ needs to be less than about 


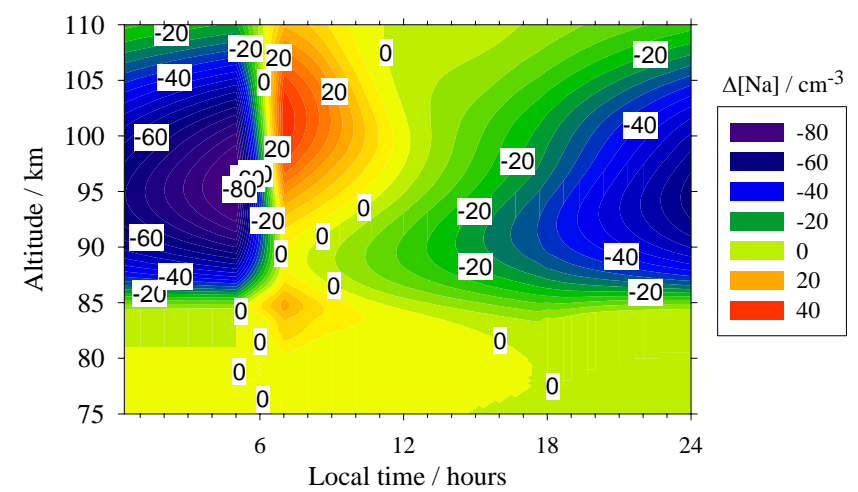

Fig. 7. Contour plot showing the difference between the $\mathrm{Na}$ atom density (atom $\mathrm{cm}^{-3}$ ), as a function of height and local time, for the case where all meteoric input occurs between 05:00 and 07:00 LT, and where the meteoric input is constant over a diurnal cycle.

$3 \times 10^{5} \mathrm{~cm}^{2} \mathrm{~s}^{-1}$ in order for molecular diffusion of $\mathrm{CO}_{2}$ to compete with eddy diffusion, and hence produce some gravitational separation (Chabrillat et al., 2002). Figure $6 \mathrm{~b}$ shows that this upper limit to $K_{z z}$ corresponds to an upper limit to the global mass input rate of about $20 \mathrm{td}^{-1}$.

Of course, one uncertainty in this analysis is the assumption in the ablation model that all the $\mathrm{Na}$ ablates in the first $5 \%$ of mass lost once the meteoroid reaches a temperature of $1200 \mathrm{~K}$ (Sect. 2.3). In fact, there is essentially no change in the Na ablation flux when the "boiling point" for Na ablation is raised to $2000 \mathrm{~K}$. This is because only a small subset of meteoroids that reach $1200 \mathrm{~K}$ do not continue heating to $2000 \mathrm{~K}$. The assumption that the Na ablates in the first mass fraction is based on a thermodynamic model of high temperature melts (Fegley and Cameron, 1987), and diffusion of $\mathrm{Na}$ through the bulk of a meteoroid should not constrain the rate of evaporation from a molten particle smaller than about $200 \mu \mathrm{m}$. There is also some uncertainty in various parameters in the ablation model, including the meteoroid density $\left(\rho_{m}\right)$, the heat capacity $(C)$, and the heat of sublimation $(\xi)$, whose values in the model are based on those of chondritic meteorites (Hunten et al., 1980). However, if all Na ablates in the initial $5 \%$ of mass lost, then the ablation flux of $\mathrm{Na}$ is not in fact sensitive to these parameters within reasonable limits (factor of 2 variation), and changing these parameters only affects the height profile of $I_{\mathrm{abl}}$.

\subsection{The diurnal variation in the meteoroid input}

Finally, we consider the sensitivity of the Na layer to the diurnal variation in meteoroid flux. In the case of radio meteors, there is a dawn peak and late afternoon minimum, in the ratio of 5:1 (Yrjola and Jenniskens, 1998). ISR observations suggest an even more sharply peaked distribution around dawn (Janches et al., 2001; Mathews et al., 2001). In order to examine the sensitivity of the $\mathrm{Na}$ layer to the diurnal variation,
NAMOD was run for two extreme cases where the integrated diurnal input was the same: 1), all the input occurs between 05:00 and 07:00 local time; and 2), the input is constant over the diurnal cycle. Figure 7 is a contour plot of the difference in the $\mathrm{Na}$ concentration between cases 1 and 2 , as a function of height and local time. While this appears to show a dramatic difference around dawn, it should be borne in mind that the peak Na concentration around $90 \mathrm{~km}$ is over $5000 \mathrm{~cm}^{-3}$ (Fig. 4c), and so the largest difference in Na concentration shown in Fig. 7 is actually only $1.5 \%$ of the concentration in the layer. This change is small because the residence time of $\mathrm{Na}$ in the layer is about 6 days, so that diurnal variations in the meteoroid input function are essentially averaged out.

\section{Conclusions}

A new time-resolved model of the Na layer (NAMOD) has been described. The model runs efficiently by solving the continuity equations for the major sodium species $\mathrm{Na}, \mathrm{Na}^{+}$ and $\mathrm{NaHCO}_{3}$ explicity, and placing the other short-lived species in steady-state. It is shown that the diurnal variation of the Na layer can be modelled satisfactorily only if sodium is permanently removed, both through dimerization of $\mathrm{NaHCO}_{3}$ and the uptake of sodium species on meteoric smoke particles that have formed from the recondensation of vaporized meteoroids.

When the sensitivity of the Na layer to the meteoroid input function is considered, a rather inconsistent picture emerges. The ratio of the column abundances of $\mathrm{Na}^{+}$to $\mathrm{Na}$ increases with the average meteoroid velocity: comparison with a limited set of $\mathrm{Na}^{+}$measurements indicates that the average meteoroid velocity is probably below $25 \mathrm{~km} \mathrm{~s}^{-1}$, as observed by conventional meteor radars. The Na column abundance is sensitive to both the meteoroid mass input rate and the vertical eddy diffusion coefficient controlling downward transport. Although there is uncertainty regarding $K_{z z}$, there is a consensus from models of gravity wave momentum deposition, and modelling the observed fall-off in the $\mathrm{CO}_{2}$ mixing ratio in the MLT, that the upper limit to $K_{z z}$ in the 80 to $90 \mathrm{~km}$ region is about $3 \times 10^{5} \mathrm{~cm}^{2} \mathrm{~s}^{-1}$. This implies that the mass input rate is less than $20 \mathrm{td}^{-1}$, close to the estimates from wide aperture incoherent scatter radars. Finally, the diurnal variation in the meteoroid input rate causes only a slight perturbation to the $\mathrm{Na}$ layer, because the residence time of $\mathrm{Na}$ in the layer is several days and diurnal effects tend to be averaged out.

Acknowledgements. This work was supported by the UK Natural Environment Research Council and the US Air Force Research Laboratory. I am grateful to R. G. Roble (High Altitude Observatory, Boulder, Colorado) for supplying output from the TIME-GCM model.

Edited by: D. Janches 


\section{References}

Baggaley, W. J.: Radar observations. In, Meteors in the Earth's Atmosphere, edited by Murad, E. and Williams, I. P., Cambridge University Press, Cambridge, 2002, 123-148.

Bilitza, D.: International reference ionosphere 2000: Examples of improvements and new features, Adv. Space Res., 31, 757-767, 2003.

Bohren, C. F. and Huffman, D. R.: Absorption and Scattering of Light by Small Particles, Wiley-Interscience, New York, 1983.

Ceplecha, Z., Borovicka, J., Elford, W. G., Revelle, D. O., Hawkes, R. L., Porubcan, V., and Simek, M.: Meteor phenomena and bodies, Space Science Rev., 84, 327-471, 1998.

Chabrillat, S., Kockarts, G., Fonteyn, D., and Brasseur, G.: Impact of molecular diffusion on the $\mathrm{CO}_{2}$ distribution and the temperature in the mesosphere, Geophys. Res. Lett., 29, art. no. 1729, 2002.

Clemesha, B. R., Simonich, D. M., Batista, P. P., and Kirchhoff, V.: The Diurnal-Variation of Atmospheric Sodium, J. Geophys. Res., 87, 181-186, 1982.

Close, S., Hunt, S., Minardi, M., and McKeen, F.: Analysis of Perseid meteor head echo data collected using the ALTAIR radar, Radio Science, 35, 1233-1240, 2000.

Cox, R. M., Self, D. E., and Plane, J. M. C.: A study of the reaction between $\mathrm{NaHCO}_{3}$ and $\mathrm{H}$ : Apparent closure on the chemistry of mesospheric Na, J. Geophys. Res., 106, 1733-1739, 2001.

Cziczo, D. J., Thomson, D. S., and Murphy, D. M.: Ablation, flux, and atmospheric implications of meteors inferred from stratospheric aerosol, Science, 291, 1772-1775, 2001.

Fegley, J. B. and Cameron, A. G. W.: A vaporization model for iron/silicate fractionation in the Mercry protoplanet, Earth Planet. Sci. Lett., 82, 207-222, 1987.

Garcia, R. R. and Solomon, S.: A new numerical model of the middle atmosphere 2. Ozone and related species, J. Geophys. Res., 99, 12 937-12 951, 1994.

Hocking, W.: Turbulence in the region $80-120 \mathrm{~km}$, Adv. Space Res., 10, 153-161, 1990.

Hughes, D. W.: Meteors. In, Cosmic Dust, edited by McDonnell, J. A. M., Wiley, London, 1978, 123-185.

Hughes, D. W.: Meteors and cosmic dust, Endeavour, 21, 31-35, 1997.

Hunten, D. M., Turco, R. P., and Toon, O. B.: Smoke and dust particles of meteoric origin in the mesosphere and stratosphere, J. Atmos. Sci., 37, 1342-1357, 1980.

Janches, D., Mathews, J. D., Meisel, D. D., and Zhou, Q. H.: Micrometeor observations using the Arecibo $430 \mathrm{MHz}$ radar I. Determination of the ballistic parameter from measured Doppler velocity and deceleration results, Icarus, 145, 53-63, 2000.

Janches, D., Meisel, D. D., and Mathews, J. D.: Orbital properties of the Arecibo micrometeoroids at earth interception, Icarus, 150, 206-218, 2001

Jones, J. and Kaiser, T. R.: The effects of thermal radiation, conduction, and meteoroid heat capacity on meteoroid ablation, Mon. Not. R. Astr. Soc., 133, 411-420, 1966.

Kalashnikova, O., Horanyi, M., Thomas, G. E., and Toon, O. B.: Meteoric smoke production in the atmosphere, Geophys. Res. Lett., 27, 3293-3296, 2000.

Kane, T. J. and Gardner, C. S.: Lidar Observations of the Meteoric Deposition of Mesospheric Metals, Science, 259, 1297-1300, 1993.
Kaufmann, M., Gusev, O. A., Grossmann, K. U., Roble, R. G., Hagan, M. E., Hartsough, C., and Kutepov, A. A.: The vertical and horizontal distribution of $\mathrm{CO}_{2}$ densities in the upper mesosphere and lower thermosphere as measured by CRISTA, J. Geophys. Res., 107, art. no. 8182, 2002.

Kopp, E.: On the abundance of metal ions in the lower ionosphere, J. Geophys. Res., 102, 9667-9674, 1997.

Koppers, G. A. A. and Murtagh, D. P.: Model studies of the influence of $\mathrm{O}_{2}$ photodissociation parameterizations in the Schumann-Runge bands on ozone related photolysis in the upper atmosphere, Ann. Geophys., 14, 68-79, 1996.

Love, S. G. and Brownlee, D. E.: Heating and thermal transformation of micrometeoroids entering the Earth's atmosphere, Icarus, 89, 26-43, 1991

Love, S. G. and Brownlee, D. E.: A direct measurement of the terrestrial mass accretion rate of cosmic dust, Science, 262, 550553, 1993.

Mathews, J. D., Meisel, D. D., Hunter, K. P., Getman, V. S., and Zhou, Q.: Very high resolution studies of micrometeors using the Arecibo $430 \mathrm{MHz}$ radar, Icarus, 126, 157-169, 1997.

Mathews, J. D., Janches, D., Meisel, D. D., and Zhou, Q. H.: The micrometeoroid mass flux into the upper atmosphere: Arecibo results and a comparison with prior estimates, Geophys. Res. Lett., 28, 1929-1932, 2001.

Mathews, J. D., Doherty, J., Wen, C.-H., Briczinski, S. J., Janches, D., and Mennucci, B.: An update on UHF radar meteor observations and associated signal processing techniques at Arecibo Observatory, J. Atmos. Solar-Terr. Phys., 65, 1139-1149, 2003.

McBride, N., Green, S. F., and McDonnell, J. A. M.: Meteoroids and small sized debris in Low Earth Orbit and at 1 au: Results of recent modelling,, Adv. Space Res., 23, 73-82, 1999.

McNeil, W. J., Murad, E. and Lai, S. T.: Comprehensive Model for the Atmospheric Sodium Layer, J. Geophys. Res., 100, 1684716855, 1995.

McNeil, W. J., Lai, S. T., and Murad, E.: Differential ablation of cosmic dust and implications for the relative abundances of atmospheric metals, J. Geophys. Res., 103, 10 899-10911, 1998.

McNeil, W. J., Murad, E., and Plane, J. M. C.: Models of meteoric metals in the atmosphere. In, Meteors in the Earth's Atmosphere, edited by Murad, E. and Williams, I. P., Cambridge University Press, Cambridge, 265-287, 2002.

Pellinen-Wannberg, A. and Wannberg, G.: Meteor observations with the European incoherent scatter UHF radar, J. Geophys. Res., 99, 11 379-11390, 1994.

Plane, J. M. C.: The Chemistry of Meteoric Metals in the Earths Upper-Atmosphere, Int. Rev. Phys. Chem., 10, 55-106, 1991.

Plane, J. M. C., Gardner, C. S., Yu, J. R., She, C. Y., Garcia, R. R., and Pumphrey, H. C.: Mesospheric Na layer at $40^{\circ} \mathrm{N}$ : Modeling and observations, J. Geophys. Res., 104, 3773-3788, 1999.

Plane, J. M. C. and Rollason, R. J.: Kinetic study of the reactions of $\mathrm{CaO}$ with $\mathrm{H}_{2} \mathrm{O}, \mathrm{CO}_{2}, \mathrm{O}_{2}$, and $\mathrm{O}_{3}$ : Implications for calcium chemistry in the mesosphere, J. Phys. Chem. A, 105, 7047-7056, 2001.

Plane, J. M. C.: Laboratory studies of meteoric metal chemistry. In, Meteors in the Earth's Atmosphere, edited by Murad, E. and Williams, I. P., Cambridge University Press, Cambridge, 289309, 2002.

Rietmeijer, F. J. M.: Interrelationships among meteoric metals, meteors, interplanetary dust, micrometeorites, and meteorites, Me- 
teor. Planet. Sci., 35, 1025-1042, 2000.

Rietmeijer, F. J. M.: Collected extraterrestrial materials: interplanetary dust particles, micrometeorites, meteorites, and meteoric dust. In, Meteors in the Earth's Atmosphere, edited by Murad, E. and Williams, I. P., Cambridge University Press, Cambridge, 215-245, 2002.

Rizk, B., Hunter, D. M., and Engel, S.: Effects of size-dependent emissivity on maximum temperatures during micrometeorite entry, J. Geophys. Res., 96, 1303-1314, 1991.

Self, D. E. and Plane, J. M. C.: Absolute photolysis cross-sections for $\mathrm{NaHCO}_{3}, \mathrm{NaOH}, \mathrm{NaO}, \mathrm{NaO}_{2}$ and $\mathrm{NaO}_{3}$ : implications for sodium chemistry in the upper mesosphere, Phys. Chem. Chem. Phys., 4, 16-23, 2002.

Singer, W., Bremer, J., Hocking, W. K., Weiss, J., Latteck, R., and Zecha, M.: Temperature and wind tides around the summer mesopause at middle and Arctic latitudes, Adv. Space Res., 31, 2055-2060, 2003.
States, R. J. and Gardner, C. S.: Thermal structure of the mesopause region (80-105 km) at $40^{\circ} \mathrm{N}$ latitude. Part II: Diurnal variations, J. Atmos. Sci., 57, 78-92, 2000.

Stoecklin, T. and Clary, D. C.: Fast Reactions between Diatomic and Polyatomic-Molecules, J. Phys. Chem., 96, 7346-7351, 1992.

von Zahn, U., Gerding, M., Hoffner, J., McNeil, W. J., and Mu$\mathrm{rad}, \mathrm{E}$. : Iron, calcium, and potassium atom densities in the trails of Leonids and other meteors: Strong evidence for differential ablation, Meteorit. Planet. Sci., 34, 1017-1027, 1999.

Wasson, J. T. and Kyte, F. T.: On the Influx of Small Comets into the Earths Atmosphere, 2. Interpretation - Comment, Geophys. Res. Lett., 14, 779-780, 1987.

Yrjola, I. and Jenniskens, P.: Meteor stream activity - VI. A survey of annual meteor activity by means of forward meteor scattering, Astron. Astrophys., 330, 739-752, 1998. 